03

\title{
Столкновение детонационных волн в пузырьковых средах
}

\author{
(C) А.И. Сычев \\ Институт гидродинамики им. М.А. Лаврентьева СО РАН, \\ 630090 Новосибирск, Россия \\ e-mail: sychev@hydro.nsc.ru
}

(Поступило в Редакцию 16 июня 2018 г.)

Экспериментально исследован процесс взаимодействия детонационных волн в пузырьковых средах при столкновении. Осуществлен процесс встречного столкновения детонационных волн в пузырьковых средах. Получены данные о критических условиях инициирования, структуре и параметрах волн детонации в пузырьковых средах. Изучены структура и свойства постдетонационных волн - волновых возмущений, образующихся при столкновении волн „пузырьковой“ детонации.

DOI: $10.21883 /$ JTF.2019.02.47066.233-18

\section{Введение}

Детонация - самоподдерживающийся процесс. Существование детонационных волн обеспечивается химической энергией, содержащейся в среде. Детонационная волна осуществляет процесс высвобождения химической энергии среды. В свою очередь, выделяющаяся энергия компенсирует энергопотери волны детонации на преобразование среды и тем самым обеспечивает процесс распространения волны. В случае перехода волны детонации из химически активной в химически неактивную среду энергетические потери волны остаются нескомпенсированными, и волна затухает.

Волновые возмущения, в которые трансформируются детонационные волны при переходе в химически неактивные (инертные) среды, определяются [1,2] как постдетонационные волны. Постдетонационные волны образуются, в частности, при переходе волны детонации в жидкость $[1,2]$ или в химически неактивную пузырьковую среду $[2,3]$ и при отражении волны пузырьковой детонации от твердой границы [2,4]. Другим примером постдетонационных волн являются волновые возмущения, в которые преобразуются детонационные волны при столкновении.

Цель настоящей работы - изучить закономерности процесса взаимодействия детонационных волн в пузырьковых средах при столкновении.

\section{Экспериментальная установка}

Экспериментальные исследования детонационных волн в пузырьковых средах проведены в вертикально расположенной ударной трубе с внутренним диаметром $40 \mathrm{~mm}$ и высотой $4.35 \mathrm{~m}$ (рис. 1), состоящей из секции низкого давления и двух секций высокого давления, расположенных сверху и снизу секции низкого давления (нижняя секция высокого давления отделена от секции низкого давления разрывной диафрагмой). Секция низкого давления высотой $3.25 \mathrm{~m}$ содержала пузырьковую среду; пузырьки диаметром $2.5 \pm 0.1 \mathrm{~mm}$ генерировались при прохождении газа через форсунку - систему капилляров, вводимых в жидкость через стенку ударной трубы в непосредственной близости от диафрагмы; давление на поверхности пузырьковой среды поддерживалось равным атмосферному. Секции высокого давления ударной трубы высотой 0.65 (верхняя) и $0.45 \mathrm{~m}$ (нижняя) заполнялись до атмосферного давления ацетилено-кислородной стехиометрической газовой смесью $\left(\mathrm{C}_{2} \mathrm{H}_{2}+2.5 \mathrm{O}_{2}\right)$, сжигание которой

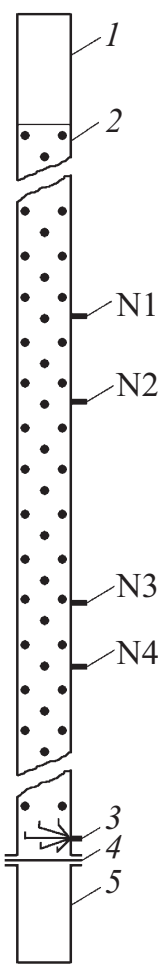

Рис. 1. Принципиальная схема экспериментальной установки: 1 - верхняя секция высокого давления, $2-$ секция низкого давления, 3 - форсунка, 4 - диафрагма, 5 - нижняя секция высокого давления; N1-N4 - датчики давления (расстояние между датчиками $\mathrm{N} 1$ и $\mathrm{N} 2, \mathrm{~N} 2$ и $\mathrm{N} 3, \mathrm{~N} 3$ и $\mathrm{N} 4-170,370$ и $70 \mathrm{~mm}$ соответственно). 

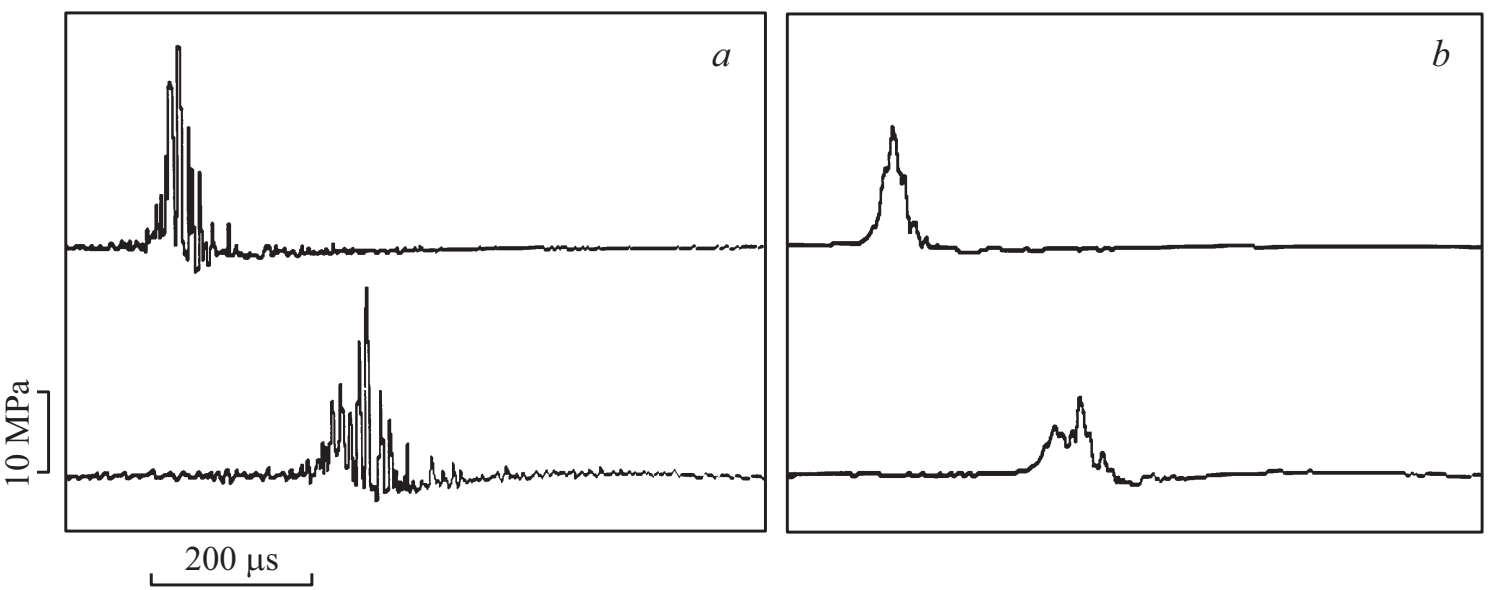

Рис. 2. Осциллограммы давления детонационной волны ДВ до $(a)$ и после $(b)$ осреднения пульсаций давления. $\alpha=0.5, \beta_{0}=0.5 \%$.

генерирует ударные волны в пузырьковой среде [5]. При этом амплитуда ударных волн соответствует давлению, развивающемуся над поверхностью пузырьковой среды при сгорании горючего газа в замкнутом объеме секции высокого давления ударной трубы [6]. Распространяющиеся навстречу друг другу ударные волны в свою очередь инициировали в химически активной пузырьковой среде встречные детонационные волны. Параметры детонационных волн (скорость распространения, давление) измеряли с помощью четырех пьезоэлектрических датчиков давления, расположенных в средней части секции низкого давления ударной трубы. Сигналы датчиков давления регистрировались цифровыми осциллографами С9-16.

Детонационные волны изучены в пузырьковых средах типа „химически неактивная жидкость - пузырьки химически активного газа“" [5] $L(\alpha)-\beta_{0}\left(\mathrm{C}_{2} \mathrm{H}_{2}+2.5 \mathrm{O}_{2}\right)$ : здесь $L(\alpha)$ - водно-глицериновый раствор с объемной концентрацией глицерина $\alpha=0.25$ или 0.5 (вязкость растворов $2.27 \cdot 10^{-3}$ и $6.84 \cdot 10^{-3} \mathrm{~Pa} \cdot \mathrm{s}$ соответственно); $\left(\mathrm{C}_{2} \mathrm{H}_{2}+2.5 \mathrm{O}_{2}\right)$ - пузырьки химически активного газа; $\beta_{0}$ - объемная концентрация газовой фазы.

\section{Экспериментальные результаты и их обсуждение}

Распространение ударной волны в пузырьковой среде вызывает сжатие пузырьков газа и воспламенение химически активных веществ, содержащихся в среде [5]. Энерговыделение в среде приводит к формированию самоподдерживающегося автоволнового стационарного процесса - волны ,пузырьковой“ детонации [6].

Детонационные волны в пузырьковых средах способны инициировать ударные волны с амплитудой, большей критической. В пузырьковых средах с $\alpha=0.5$ при $\beta_{0}=0.5$ и $1 \%$ ударные волны, инициирующие детонационные волны, распространяющиеся в пузырьковой среде сверху вниз (ВДВ - „верхняя“ детонационная волна) и снизу вверх (НДВ - „нижняя““ детонационная волна),

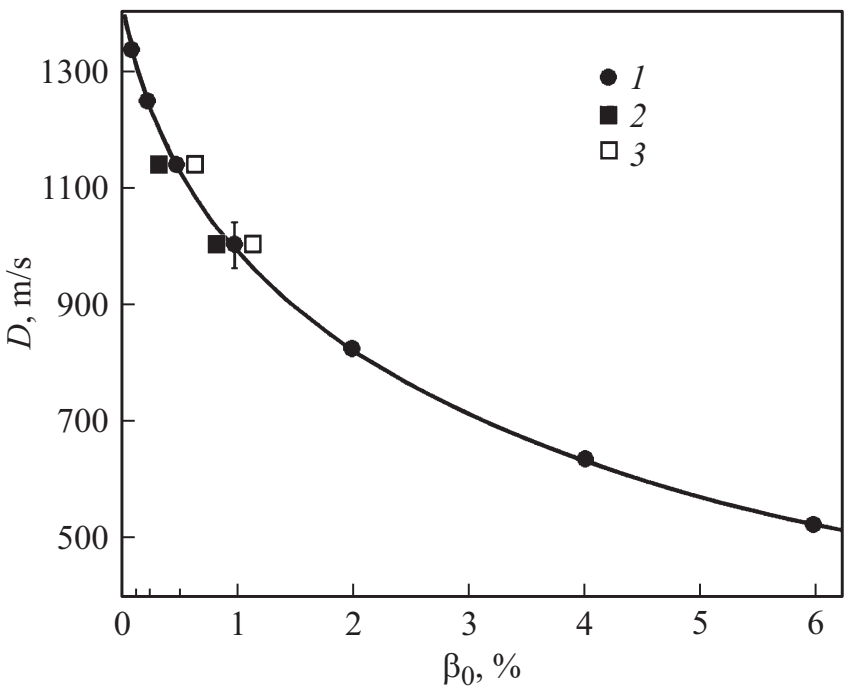

Рис. 3. Зависимости скорости $D\left(\beta_{0}\right)$ волн детонации ДВ $(1)$, ВДВ (2) и НДВ (3). $\alpha=0.5$.

имеют критические амплитуды $\leq 1.7 \mathrm{MPa,} \mathrm{совпадающие}$ с величиной критической амплитуды ударной волны, инициирующей одиночную детонационную волну (ДВ).

Структура детонационных волн ВДВ, НДВ и ДВ качественно идентична: волны „Пузырьковой“ детонации это уединенные волны с пульсационным профилем давления (рис. 2,a). Пульсации давления являются следствием генерирования ударных волн пузырьками газа, воспламенившихся в результате сжатия в волне детонации. Стохастичность пульсаций давления обусловлена хаотичностью распределения пузырьков газа в жидкости. Регистрируемая амплитуда пульсаций давления, длительность которых составляет $3-5 \mu \mathrm{s}$, достигает $15-30 \mathrm{MPa}$.

Осреднение пульсаций давления позволяет получить эффективный профиль давления волны детонации (рис. 2,b). Сигналы датчиков давления осреднялись с 


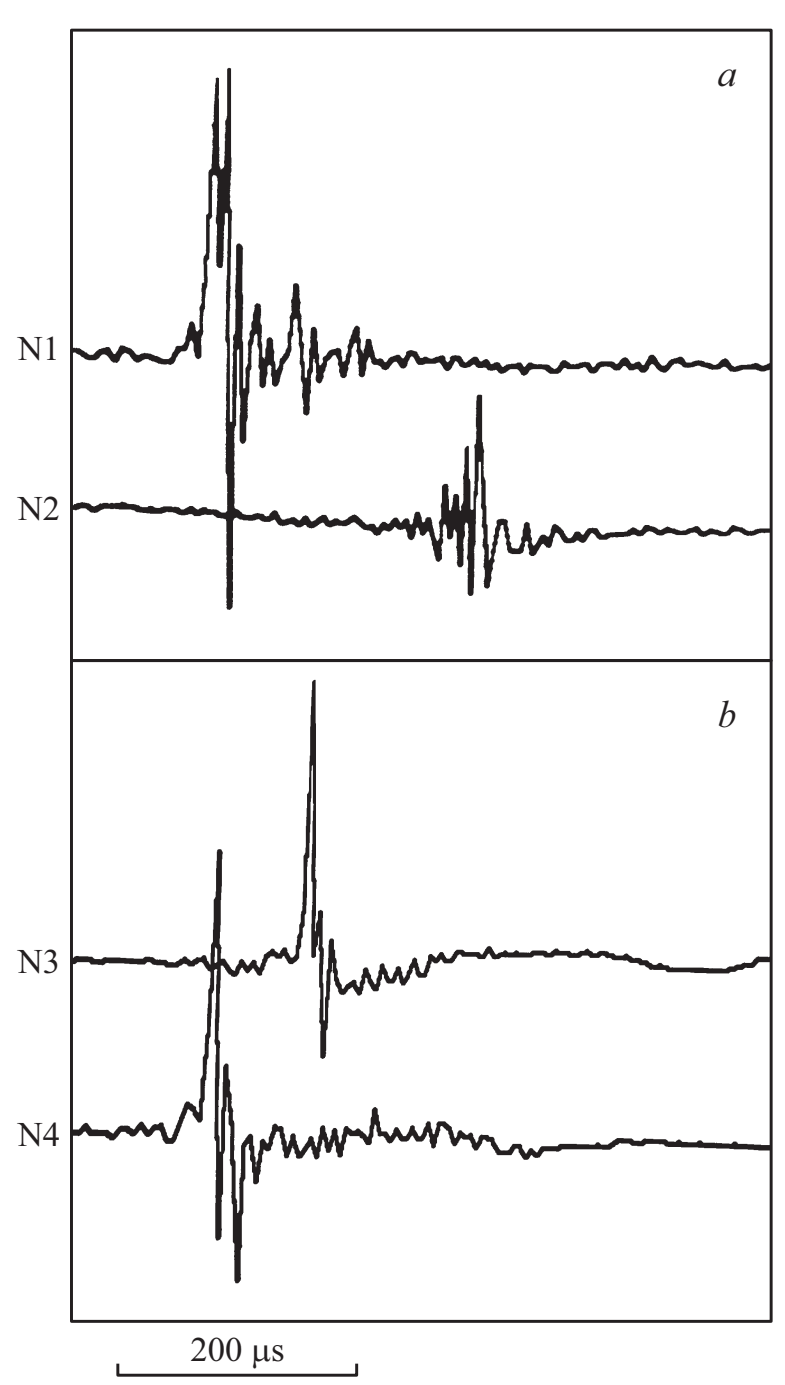

Рис. 4. Осциллограммы давления детонационных волн ВДВ $(a)$ и НДВ $(b) . \alpha=0.5, \beta_{0}=1 \%$.

использованием штатной процедуры цифрового осциллографа С9-16 по 10 точкам при временно́м интервале между точками (времени дискретизации), равном $1 \mu \mathrm{s}$. Детонационные волны с осредненными пульсациями давления это уединенные волны, давление за которыми релаксирует к величине, близкой к давлению перед волной. Эффективное (осредненное по пульсациям) давление детонационных волн в исследованных пузырьковых средах составляет 6-8 МРа. Длительность детонационных волн (временна́я характеристика, определяемая на нулевом уровне осредненного по пульсациям сигнала датчика давления) равна $50-70 \mu \mathrm{s}$.

Детонационные волны в пузырьковых средах распространяются со скоростью, большей равновесной скорости звука в пузырьковой среде, но меньшей скорости звука в жидкости. На рис. 3 представлены результаты измерения скорости $D$ в пузырьковых средах при различных концентрациях газовой фазы среды $\beta_{0}$ (каждая точка - среднее данных 5-10 опытов). Характер зави- симостей $D\left(\beta_{0}\right)$ детонационных волн ДВ, ВДВ и НДВ является общим: с увеличением концентрации газовой фазы пузырьковой среды $\beta_{0}$ скорость волн детонации $D$ снижается.

Таким образом, критические условия инициирования, структура и свойства волн ,пузырьковой“ детонации ДВ, ВДВ и НДВ совпадают - детонационные волны ДВ, ВДВ и НДВ идентичны. Детонация в пузырьковых средах это автоволновой процесс: характеристики детонационных волн не зависят от условий инициирования и определяются параметрами и свойствами пузырьковой среды.

На рис. 4 зарегистрировано встречное взаимодействие детонационных волн: сигналы датчиков $(\mathrm{N} 1, \mathrm{~N} 2)$ и (N3, N4) - осциллограммы давления детонационных волн ВДВ и НДВ соответственно, полученные в одном опыте. В этом случае столкновение детонационных волн ВДВ и НДВ произошло на участке ударной трубы между датчиками N2 и N3.

Детонация - самоподдерживающийся процесс. Существование детонационных волн обеспечивается энерговыделением в среде. При этом распространение волн детонации приводит к необратимому преобразованию среды - детонацию можно представить как процесс, переводящий среду из химически активного в химически неактивное состояние. Волны, в которые трансформируются детонационные волны ВДВ и НДВ после столкновения (постдетонационные волны), распространяются уже по химически неактивной среде. Отсутствие энерговыделения в среде приводит (вследствие действия диссипативных процессов) к затуханию постдетонационных волн. На рис. 4 не наблюдается постдетонационных волн; данный факт позволяет сделать вывод о том, что постдетонационные волны при данных начальных параметрах пузырьковой среды затухают на расстоянии $<185 \mathrm{~mm}$ (половина расстояния между датчиками N2 и N3).

Чрезвычайно быстрое затухание постдетонационных волн и стохастичность самого процесса взаимодействия детонационных волн не позволяют проследить динамику постдетонационных волн, образующихся при взаимодействии волн пузырьковой детонации. С учетом данного обстоятельства заметим, что образующиеся при взаимодействии волн „пузырьковой“ детонации постдетонационные волны, распространяющиеся от границы взаимодействия детонационных волн, аналогичны постдетонационной волне, в которую трансформируется волна детонации при отражении от твердой преграды. Исследования процесса отражения детонационных волн от твердой преграды позволяют получить данные о свойствах постдетонационных волн.

Параметры детонационной и отраженной волн регистрировали на различных расстояниях от торца ударной трубы $(x=6-180 \mathrm{~mm})$. Волна „пузырьковой“ детонации имеет пульсационную структуру (рис. $5, a$ ). Пульсации давления меньшей амплитуды наблюдаются и в отраженной волне (рис. $5, a)$. 


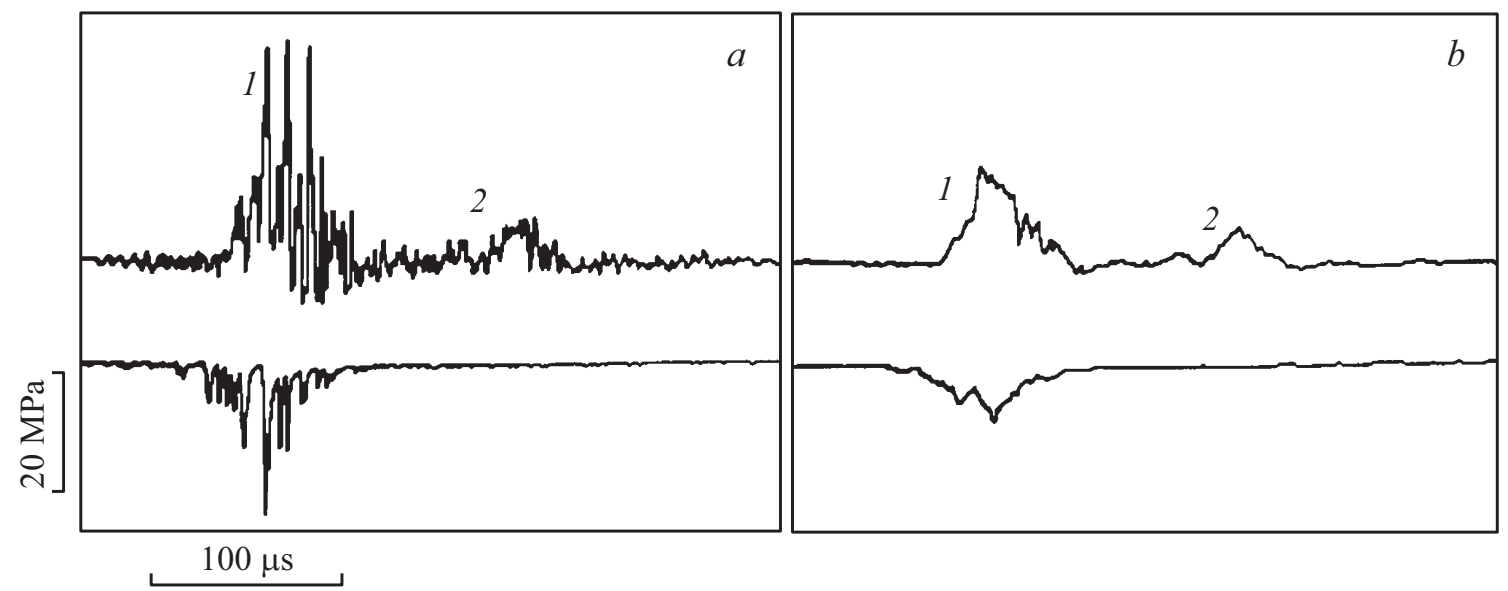

Рис. 5. Осциллограммы давления детонационной (1) и отраженной (2) волн (верхний луч) и свечения пузырьковой среды (нижний луч). $\alpha=0.5, \beta_{0}=1 / 4 \%, x=80 \mathrm{~mm} ; a-$ до осреднения пульсаций давления, $b-$ после осреднения пульсаций давления.

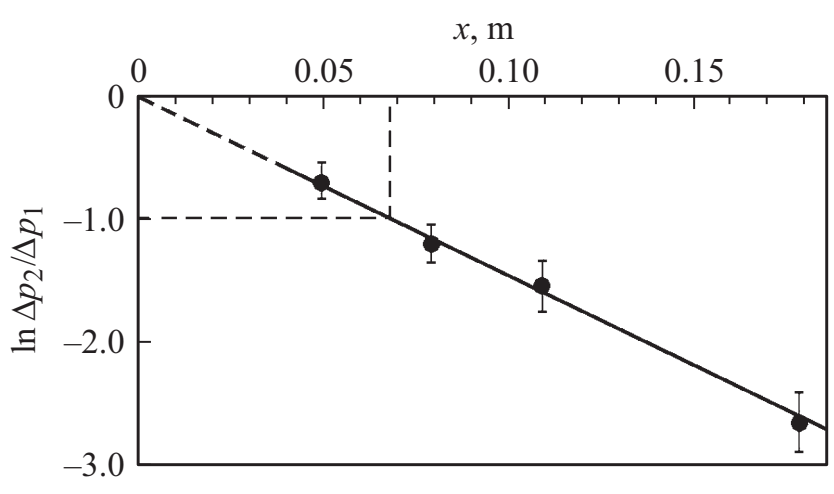

Рис. 6. Зависимость $\ln \left(\Delta p_{2} / \Delta p_{1}\right)(x) . \alpha=0.5, \beta_{0}=1 / 4 \%$.

Свечение пузырьковой среды, являющееся следствием воспламенения пузырьков газа в волне детонации, также имеет пульсационный характер (рис. 5,a). В отраженной волне свечение пузырьковой среды отсутствует (рис. 5,a). Отраженная волна, образующаяся при взаимодействии волны детонации с твердой преградой, распространяется в химически неактивной среде и является, таким образом, постдетонационной волной.

Волна „пузырьковой“ детонации и отраженная волна с осредненными пульсациями давления это уединенные волны, давление за которыми релаксирует к значению, близкому к начальному давлению в пузырьковой среде.

Для описания детонационной и отраженной волн введем следующие характеристики волн: $p_{1}$ и $p_{2}-$ амплитуда (осредненное по пульсациях давление в максимуме) детонационной и отраженной волн соответственно; $\tau_{1}$ и $\tau_{2}$ - длительность (временна́я характеристика, определяемая на нулевом уровне осредненного по пульсациям сигнала датчика давления) детонационной и отраженной волн соответственно; $\lambda_{1}=D_{1} \cdot \tau_{1}$ и $\lambda_{2}=D_{2} \cdot \tau_{2}$ - линейная протяженность (длина) детонационной и отраженной волн соответственно (здесь
$D_{1}$ и $D_{2}-$ скорости распространения детонационной и отраженной волн соответственно).

Результаты измерений осредненного давления отраженной волны $p_{2}$ представлены на рис. 6 в виде логарифмической зависимости отношения давлений $\Delta p_{2} / \Delta p_{1}$ от расстояния пробега волны $x$ (здесь $\Delta p_{2}=p_{2}-p_{0}$, $\Delta p_{1}=p_{1}-p_{0}$, осредненное по пульсациям давление детонационных волн $p_{1}=6-8 \mathrm{MPa}, p_{0}=0.1 \mathrm{MPa}-$ начальное давление пузырьковой среды).

Зависимость относительного давления отраженной (постдетонационной) волны от расстояния выражается соотношением $\Delta p_{2} / \Delta p_{1}=\exp (-k \cdot x)$; здесь $k-$ постоянная затухания (коэффициент ослабления) постдетонационной волны. Значения $k$ представлены на рис. 7 (каждая точка - среднее нескольких измерений). Величина $k$ возрастает при увеличении концентрации газовой фазы и вязкости жидкого компонента пузырьковой среды. Отметим, что полученная на основании анализа рис. 4 экспериментальная оценка расстояния затухания постдетонационных волн, образующихся при

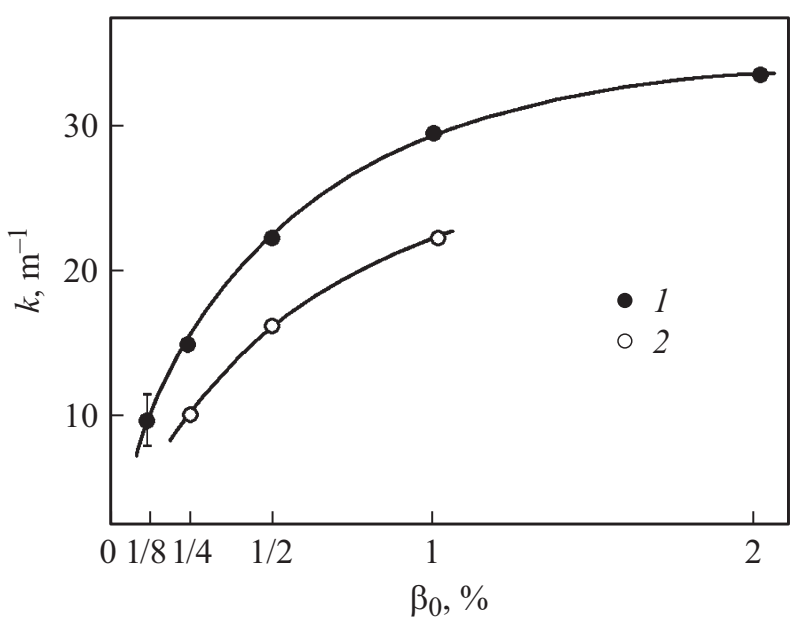

Рис. 7. Зависимости $k\left(\beta_{0}\right) . \alpha=0.5$ (1) и 0.25 (2). 


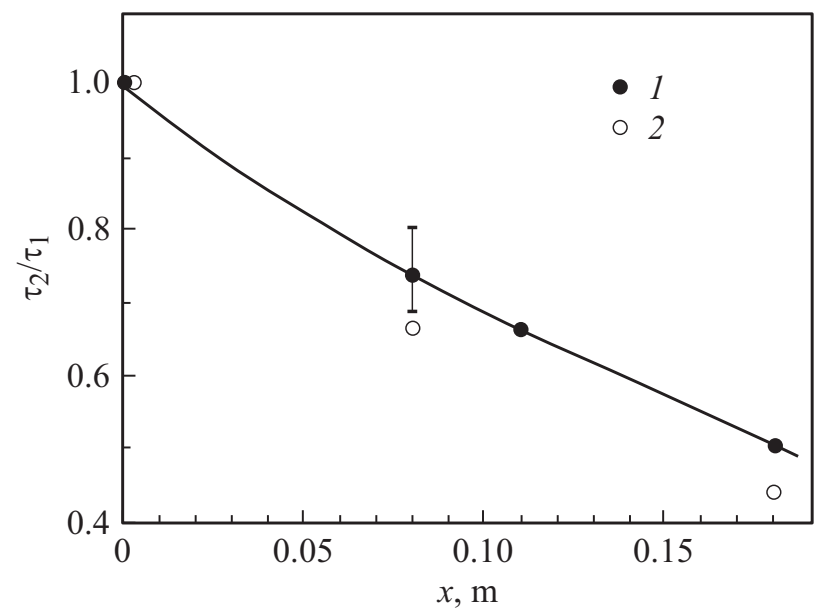

Рис. 8. Зависимости $\tau_{2} / \tau_{1}(x) . \alpha=0.5$ (1) и $0.25(2)$.

встречном столкновении волн детонации, согласуется с приведенными на рис. 7 данными.

Скорость распространения отраженных волн в исследованном диапазоне расстояний от торца ударной трубы постоянна и примерно равна скорости детонационных волн: $D_{2}=(1.0 \pm 0.1) \cdot D_{1}$.

Линейная протяженность детонационных волн $\lambda_{1}$ в исследованных пузырьковых средах (рис. 3) составляет $3-8 \mathrm{~cm}$ (длительность волн $\tau_{1} \approx 60 \mu \mathrm{s}$ ). Линейная протяженность отраженной волны $\lambda_{2}$ вблизи от твердой преграды равна длине детонационной волны $\left(\lambda_{2} \approx \lambda_{1}\right)$ и уменьшается по мере дальнейшего распространения: несмотря на то, что скорость отраженной волны с расстоянием пробега остается примерно постоянной $\left(D_{2} \approx D_{1}\right)$, длительность волны $\tau_{2}$ при этом уменьшается (рис. 8).

\section{Заключение}

Экспериментально исследован процесс столкновения детонационных волн в пузырьковых средах. Установлено, что детонационные волны, распространяющиеся в пузырьковой среде как сверху вниз, так и снизу вверх, идентичны одиночным волнам „пузырьковой“ детонации. Инициировать детонационные волны в пузырьковых средах способны ударные волны с амплитудой, большей критической. Волны „пузырьковой“ детонации это уединенные волны с пульсационным профилем давления. Пульсации давления являются следствием генерирования ударных волн пузырьками газа, воспламенившихся в результате сжатия в волне детонации. Детонационные волны с осредненными пульсациями давления это уединенные волны, давление за которыми релаксирует к величине, близкой к давлению перед волной. Детонационные волны в пузырьковых средах распространяются со скоростью, большей равновесной скорости звука в пузырьковой среде, но меньшей скорости звука в жидкости. С увеличением концентрации газовой фазы пузырьковой среды скорость волн детонации снижается.

При столкновении волны „пузырьковой“ детонации „аннигилируют“ - трансформируются в постдетонационные волны, затухающие на расстоянии нескольких длин детонационных волн. Установлено, что постдетонационные волны имеют, также как и волна детонации, пульсационную структуру; постдетонационные волны с осредненными пульсациями давления это уединенные волны, давление за которыми релаксирует к значению, близкому к начальному давлению в пузырьковой среде. Скорость распространения постдетонационных волн постоянна и примерно равна скорости детонационных волн. Длительность постдетонационных волн с расстоянием пробега уменьшается. Давление постдетонационных волн спадает по экспоненциальному закону. Коэффициент затухания постденонационных волн возрастает при увеличении концентрации газовой фазы и вязкости жидкого компонента пузырьковой среды.

\section{Список литературы}

[1] Сычев А.И. // Физика горения и взрыва. 2002. Т. 38. № 2. C. $99-103$.

[2] Сычев А.И. // Динамика сплошной среды. Акустика неоднородных сред. 2007. Вып. 124. С. 29-36.

[3] Сычев А.И. // Физика горения и взрыва. 2001. Т. 37. № 4. C. $96-99$.

[4] Сычев А.И. // Физика горения и взрыва. 2000. Т. 36. № 3. C. $107-113$.

[5] Сычев А.И. // Физика горения и взрыва. 1985. Т. 21. № 2. C. $130-134$.

[6] Сычев А.И. // Физика горения и взрыва. 1985. Т. 21. № 3. C. $103-110$. 